
UNDER CONTRACT DE-AC02-76CH03073

PPPL-3563

PPPL-3563

UC-70

\title{
Characteristics of the First H-mode Discharges in NSTX
}

\author{
R. Maingi, M.G. Bell, R.E. Bell, C.E. Bush, E.D. Fredrickson, D.A. Gates,
} S.M. Kaye, H.W. Kugel, B.P. LeBlanc, J.E. Menard, D. Mueller, S.A. Sabbagh,

D. Stutman, G. Taylor, D.W. Johnson, R. Kaita, R.J. Maqueda, M. Ono, F. Paoletti, Y-K.M. Peng, A.L. Roquemore, C.H. Skinner, V.A. Soukhanovskii, and E.J. Synakowski

May 2001
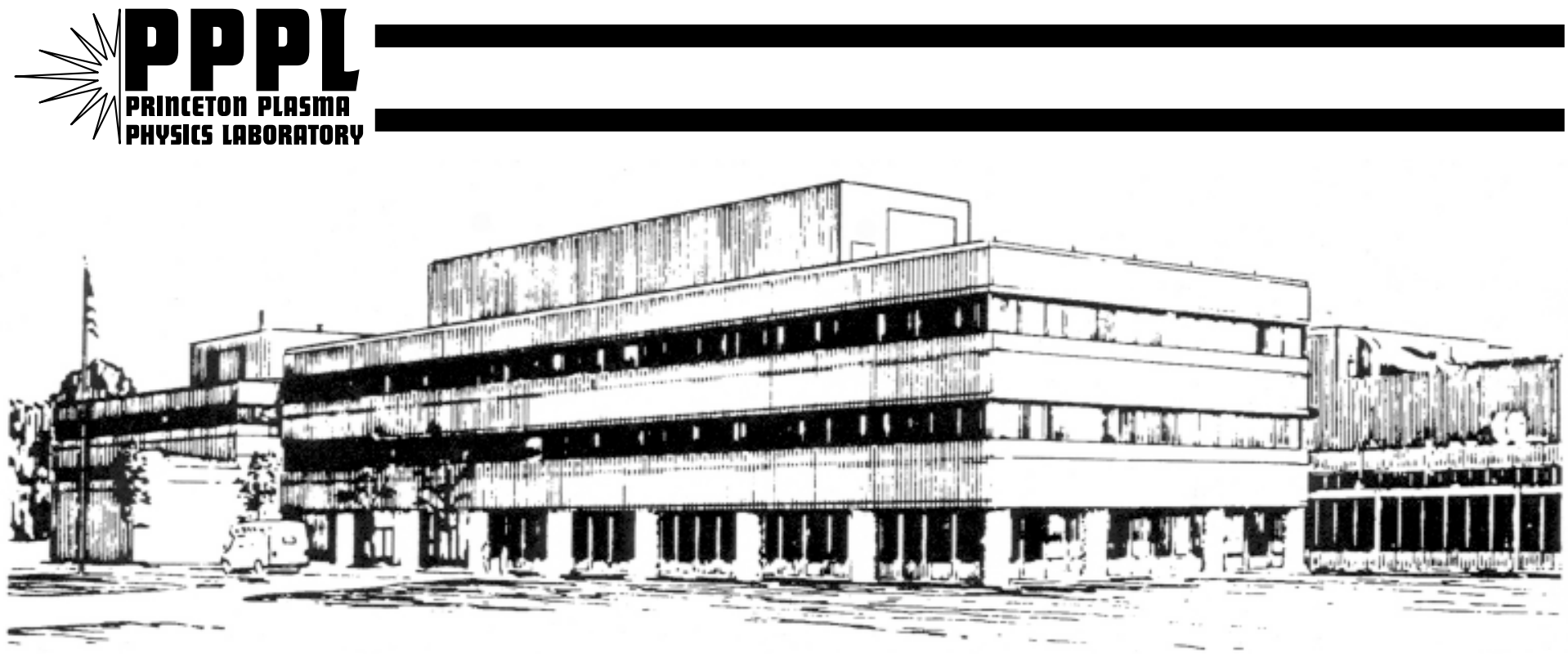

PRINCETON PLASMA PHYSICS LABORATORY PRINCETON UNIVERSITY, PRINCETON, NEW JERSEY 


\section{PPPL Reports Disclaimer}

This report was prepared as an account of work sponsored by an agency of the United States Government. Neither the United States Government nor any agency thereof, nor any of their employees, makes any warranty, express or implied, or assumes any legal liability or responsibility for the accuracy, completeness, or usefulness of any information, apparatus, product, or process disclosed, or represents that its use would not infringe privately owned rights. Reference herein to any specific commercial product, process, or service by trade name, trademark, manufacturer, or otherwise, does not necessarily constitute or imply its endorsement, recommendation, or favoring by the United States Government or any agency thereof. The views and opinions of authors expressed herein do not necessarily state or reflect those of the United States Government or any agency thereof.

\section{Availability}

This report is posted on the U.S. Department of Energy's Princeton Plasma Physics Laboratory Publications and Reports web site in Calendar Year 2001. The home page for PPPL Reports and Publications is: http://www.pppl.gov/pub_report/

DOE and DOE Contractors can obtain copies of this report from:

U.S. Department of Energy

Office of Scientific and Technical Information

DOE Technical Information Services (DTIS)

P.O. Box 62

Oak Ridge, TN 37831

Telephone: (865) 576-8401

Fax: (865) 576-5728

Email: reports@adonis.osti.gov

This report is available to the general public from:

National Technical Information Service

U.S. Department of Commerce

5285 Port Royal Road

Springfield, VA 22161

Telephone: 1-800-553-6847 or

(703) 605-6000

Fax: (703) 321-8547

Internet: http://www.ntis.gov/ordering.htm 


\section{Characteristics of the First H-mode Discharges in NSTX}

R. Maingi ${ }^{\mathrm{a}}$, M.G. Bell ${ }^{\mathrm{b}}$, R.E. Bell ${ }^{\mathrm{b}}$, C.E. Bush ${ }^{\mathrm{a}}$, E.D. Fredrickson ${ }^{\mathrm{b}}$, D.A. Gates ${ }^{\mathrm{b}}$, S.M.

Kaye $^{\text {b }}$, H.W. Kugel ${ }^{\mathrm{b}}$, B.P. LeBlanc ${ }^{\mathrm{b}}$, J.E. Menard ${ }^{\mathrm{b}}$, D. Mueller ${ }^{\mathrm{b}}$, S.A. Sabbagh ${ }^{\mathrm{c}}$, D.

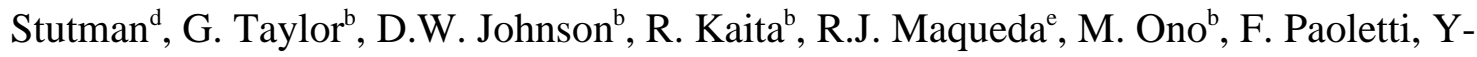

K.M. Peng ${ }^{\mathrm{a}}$, A.L. Roquemore ${ }^{\mathrm{b}}$, C.H. Skinner ${ }^{\mathrm{b}}$, V.A. Soukhanovskii ${ }^{\mathrm{b}}$, E.J. Synakowski ${ }^{\mathrm{b}}$

${ }^{a}$ Oak Ridge National Laboratory, Oak Ridge TN, 37831 USA

${ }^{b}$ Princeton Plasma Physics Laboratory, PO Box 451, Princeton, NJ, 08543 USA

${ }^{c}$ Columbia University, New York, NY, USA

${ }^{d}$ Johns Hopkins University, Baltimore, MD, USA

${ }^{e}$ Los Alamos National Laboratory, Los Alamos, NM, 87545 USA

(Received

\section{$\underline{\text { Abstract }}$}

We report observations of the first low-to-high $(\mathrm{L}-\mathrm{H})$ confinement mode transitions in the National Spherical Torus Experiment (NSTX). The H-mode energy confinement time increased over reference L-mode discharges transiently by $100-300 \%$, as high as 150ms. This confinement time is $\sim 1.8-2.3$ times higher than predicted by a multimachine ELM-free H-mode scaling. This achievement extends the $\mathrm{H}$-mode window of fusion devices down to a record low aspect ratio $(\mathrm{R} / \mathrm{a}) \sim 1.3$, challenging both confinement and L-H power thresholds scalings based on conventional aspect ratio tokamaks.

PACS numbers: 52.55.Fa

\section{Introduction}

Spontaneous transitions from a low confinement (L-mode) to a high confinement regime (H-mode) have been observed ${ }^{1}$ in fusion experiments for many years. H-modes 
offer an improved confinement time for both energy $\left(\tau_{E}\right)$ and particles $\left(\tau_{p}\right)$ in fusion plasmas, and are potentially attractive reactor operational scenarios because they can lead to self-sustained fusion burn in relatively small, low cost devices.

The concept of a low aspect ratio toroidally symmetric device (spherical torus or ST) was proposed ${ }^{2}$ many years ago, and test facilities were constructed in the mid-1990's. The first ST to demonstrate ${ }^{3} \mathrm{H}$-mode operation was the START device in Culham, England. The heating power requirement for accessing the H-mode regime (power threshold) in START was significantly higher than predicted by a multi-machine database $^{4}$ compiled from conventional aspect ratio tokamaks. Recently H-mode transitions were reported ${ }^{5}$ from the MAST device in Culham also; both START and MAST have R/a 1.5-1.6. We report in this paper the observation of H-mode transitions in the National Spherical Torus Experiment (NSTX), extending the START/MAST results to record low aspect ratio $\sim 1.3$. This achievement challenges and extends the existing international power threshold and energy confinement time scalings ${ }^{6}$ based on conventional aspect ratio tokamaks. The remainder of this paper discusses characteristics of the H-modes in NSTX.

NSTX is a relatively new fusion research facility ${ }^{7,8}(\mathrm{R}=0.85 \mathrm{~m}, \mathrm{a}=0.67 \mathrm{~m}, \mathrm{R} / \mathrm{a} \geq 1.26$, $B_{t} \leq 0.6 T$ ), which commenced physics operation in July 1999. NSTX was designed for operation at $1 \mathrm{MA}$ of plasma current $\left(\mathrm{I}_{\mathrm{p}}\right)$ and has achieved ${ }^{9} 1.07$ MA to date. Auxiliary heating systems include a neutral beam injector (NBI), capable of delivering $5 \mathrm{MW}$ to NSTX, and a radio-frequency system designed for $6 \mathrm{MW}$ input power. All of the plasma facing components on the center stack and divertor are clad in graphite armor. NSTX employs a conventional wall conditioning $\operatorname{program}^{10}$, which includes center stack resistive bake-out up to $300 \mathrm{deg}$. C, glow discharge cleaning, and boronization ${ }^{11,12}$. 


\section{H-mode discharge signatures}

H-modes in NSTX have characteristics similar to tokamak H-modes. Fig. 1 compares the characteristics of the longest H-mode duration obtained to date in NSTX with an Lmode reference discharge. These discharges had $\mathrm{I}_{\mathrm{p}}=1 \mathrm{MA}$ and neutral beam injection power $\left(\mathrm{P}_{\mathrm{NBI}}\right)=1.5 \mathrm{MW}$ (Fig. 1a, 1b). Edge visible light, measured by filtered visible spectroscopy (e.g, $\mathrm{D}_{\alpha}$ in Fig. 1c) and a fast visible camera, was reduced on a 1 ms time scale in the H-mode discharge. NSTX had 3 separate spectroscopic views with 12 total channels, measuring deuterium, carbon, boron, oxygen, and helium line radiation; light emission was reduced simultaneously on all these channels. Visible light is emitted from the edge plasma and increases with the local electron density $\left(\mathrm{n}_{\mathrm{e}}\right)$. These simultaneous drops indicate a drop in the edge $\mathrm{n}_{\mathrm{e}}$, as often observed during H-mode transitions in tokamaks. While the scrape-off layer $n_{e}$ decreases, the $n_{e}$ just inside the magnetic separatrix increases during NSTX H-mode discharges, i.e. a steep $n_{e}$ gradient is observed. Fig. 2 compares the electron density, electron temperature $\left(\mathrm{T}_{e}\right)$, and electron pressure $\left(\mathrm{P}_{\mathrm{e}}\right)$ profiles from Thomson scattering for the discharges in Fig. 1. The H-mode transition occurred at $\mathrm{t}=191 \mathrm{~ms}$ in discharge $\# 104312$, and evidence of an increase in the edge $n_{e}$ gradient relative to the L-mode reference was shown by the first Thomson laser pulse following the transition at $\mathrm{t}=197 \mathrm{~ms}$. The $\mathrm{n}_{\mathrm{e}}$ profile continued to evolve and actually developed a hump at the edge by $\mathrm{t}=230 \mathrm{~ms}$ in the $\mathrm{H}$-mode discharge. The $\mathrm{T}_{\mathrm{e}}$ profile responded to the improved $\mathrm{H}$-mode confinement on a longer time scale, and evidence of a weak $T_{e}$ pedestal was observed at $t=230 \mathrm{~ms}$ in the $\mathrm{H}$-mode case. The broader $\mathrm{n}_{\mathrm{e}}$ and $\mathrm{T}_{\mathrm{e}}$ profiles in the H-mode lead to a decrease in the pressure peaking factor $\left(\mathrm{P}_{\text {peak }} \equiv \mathrm{P}_{0} / \mathrm{P}_{\mathrm{av}}\right.$, with $\mathrm{P}_{0}=$ central pressure and $\mathrm{P}_{\mathrm{av}}=$ volume average pressure) computed with EFIT, from 2.4 in the L-mode down to as low as 2.1. The electron kinetic pressure peaking factor $\left(\mathrm{P}_{\text {peak }, e} \equiv \mathrm{P}_{0, e} / \mathrm{P}_{\mathrm{av}, \mathrm{e}}\right.$, obtained from the raw profiles in Fig. 2) also decreased, from 3.7 in the 
L-mode reference case to 3.1 in the $\mathrm{H}$-mode discharge at $\mathrm{t}=230 \mathrm{~ms}$, due primarily to the flattening of the $\mathrm{n}_{\mathrm{e}}$ profile.

During the $\mathrm{H}$-mode phase, an enhanced signal was observed (fig. 1d) on the electron Bernstein wave (EBW) emission ${ }^{13}$. Mode conversion of electrostatic Electron Bernstein waves to electromagnetic, $\mathrm{X}$-mode radiation becomes more efficient with the increased edge $\mathrm{n}_{\mathrm{e}}$ gradient during the H-mode. Thus, the prompt increase on the radiometer signal following the $\mathrm{L}-\mathrm{H}$ transition serves as a useful identification of $\mathrm{H}$-mode phases.

The energy confinement in H-modes in conventional aspect ratio tokamaks increases typically by $60-80 \%$ over L-mode levels. This increase in $\tau_{\mathrm{E}}$ has previously been correlated with reduced transport at the edge (and sometimes in the core), as manifested in steep edge $\mathrm{n}_{\mathrm{e}}$ gradients, and the reduced transport is in turn caused by a reduction in the turbulence levels. A signature of the reduced edge turbulence in the NSTX H-modes was observed on the center stack Mirnov signals in Fig. 1e. Fig. 1f shows the L-mode reference case. Note that the envelope of the oscillations was gradually reduced as the plasma X-point was formed at 170ms in both discharges, but that the H-mode discharge exhibited a rapid drop at the L-H transition. However the fluctuation level in the $\mathrm{H}$-mode discharge began to increase slowly at $245 \mathrm{~ms}$, indicating the onset of new magnetohydrodynamic (MHD) activity (discussed later).

The peak stored energy, obtained by magnetic equilibrium reconstruction with the EFIT code $^{14}$, increased by $60 \%$ in the $\mathrm{H}$-mode phase compared with the L-mode reference discharge (fig. 1g). These values correspond to toroidal beta $\left(\beta_{\mathrm{l}} \equiv 2 \mu_{0} \mathrm{P}_{\mathrm{av}} / \mathrm{B}_{\mathrm{t}}{ }^{2}\right)$ of $10 \%$ and $6 \%$ respectively. The peak rate of rise of both the plasma stored energy, $\mathrm{dW} / \mathrm{dt}$, and the plasma electron inventory, $\mathrm{dN}_{\mathrm{e}} / \mathrm{dt}$, increased by more than $100 \%$ in the $\mathrm{H}$-mode phase, up to $1.7 \mathrm{MW}$ and $2.3 \times 10^{20}$ electrons/s respectively. We mention that the Lmode reference discharge in figs. 1-2 had gas puffing to achieve comparable line-average 
density prior to the L-H transition in the H-mode discharge. This gas puffing apparently reduced $\tau_{\mathrm{E}}$ to $\leq 35 \mathrm{~ms}$ in the reference discharge. In comparison, lower density L-modes in NSTX achieved peak $\tau_{\mathrm{E}} \leq 50 \mathrm{~ms}$ and stored energy $\sim 100 \mathrm{~kJ}$.

The estimated $\tau_{\mathrm{E}}$ during the H-mode phase (fig. $1 \mathrm{~h}$ ) varied between $70 \mathrm{~ms}$ and $150 \mathrm{~ms}$, and was up to 4 times higher than the L-mode reference discharge shown. A useful normalization is the confinement time predicted by an international edge localized mode (ELM)-free H-mode scaling ${ }^{6}$, which is based on neutral-beam heated, high- $\beta$, conventional aspect ratio tokamaks with $(\mathrm{R} / \mathrm{a})>2.5$. The confinement time from this scaling is given by $\tau_{\mathrm{E}}^{\text {ELM-free }}=.0314 \mathrm{I}_{\mathrm{p}}^{0.94} \mathrm{~B}_{\mathrm{t}}^{0.27} \mathrm{n}^{0.34} \mathrm{P}_{\text {loss }}{ }^{-0.68} \mathrm{R}^{1.98} \kappa^{0.68}(\mathrm{a} / \mathrm{R})^{0.10} \mathrm{M}^{0.43}$, where $\mathrm{I}_{\mathrm{p}}$, $\mathrm{B}_{\mathrm{t}}, \mathrm{n}$ (plasma density), $\mathrm{P}_{\text {loss }}$ (power through separatrix), $\mathrm{R}$, and $\mathrm{M}$ (working gas mass) have units of MA, T, $10^{19} \mathrm{~m}^{-3}, \mathrm{MW}, \mathrm{m}$, atomic mass units respectively, and $\kappa$ and $\mathrm{a} / \mathrm{R}$ are dimensionless. The discharge in fig. 1 achieved up to $1.8-2.3$ times the $65 \mathrm{~ms} \tau_{\mathrm{E}}^{\text {ELM-free }}$ predicted for NSTX parameters. A second commonly-used H-mode scaling IBP98(y,2), based $^{6}$ on ELMy H-mode discharges, predicted a $\tau_{\mathrm{E}}$ of $\sim 100-120 \mathrm{~ms}$ for NSTX, i.e. actually higher than the ELM-free scaling. The excellent performance of NSTX relative to either of these scalings underscores the significance of achieving $\mathrm{H}$-mode, which will lead to an extension of the databases and scalings to low aspect ratio.

Finally, a pronounced signature of the H-mode phase is the formation of a peripherally peaked shell in the ultra-soft X-ray (USXR) spectral region from 10-100 Angstroms. Fig. 3 shows the USXR emission from another H-mode discharge (\#104316), which had an L-H transition at $\mathrm{t}=202 \mathrm{~ms}$. Before the L-H transition (i.e. $\mathrm{t}_{1}=194 \mathrm{~ms}$ ), the USXR profile was quite broad. The edge peaking began soon after the transition (i.e. $t_{2}=214 \mathrm{~ms}$ ) and continued to become more peaked prior to termination (i.e. $t_{3}=250 \mathrm{~ms}$ ). After the H-mode termination, the USXR profile resumed a broad shape, i.e. for $\mathrm{t}>260 \mathrm{~ms}$ 
in the H-mode case. A similar H-mode discharge was modeled with the MIST code ${ }^{15}$. This analysis showed that the $\mathrm{H}$-mode phase had a strong impurity transport barrier, evidenced by a 10x reduction in cross-field carbon particle flux compared to the L-mode phase. In addition, total radiated power (not shown) typically dropped just after the L-H transition as well, but then increased during the ELM-free phases of the longer duration H-modes.

\section{$\underline{\text { H-mode operating window and reproducibility }}$}

H-mode access for NSTX has been observed in the following range of conditions: 0.7 $\leq \mathrm{I}_{\mathrm{p}} \leq 1 \mathrm{MA}, \mathrm{B}_{\mathrm{t}}=0.45 \mathrm{~T}, 0.85 \mathrm{MW} \leq \mathrm{P}_{\mathrm{NBI}} \leq 1.6 \mathrm{MW}, 0.6 \mathrm{MW} \leq \mathrm{P}_{\mathrm{OH}} \leq 0.8 \mathrm{MW}$ (ohmic heating power), $2 \times 10^{19} \leq \overline{n_{e}} \leq 2.5 \times 10^{19} \mathrm{~m}^{-3}$, inner-wall gap $\geq 1-2 \mathrm{~cm}$, and only in lower-single null diverted shape. In this configuration, the ion-Grad B drift direction was toward the X-point. To date, no center-stack limiter H-modes have been observed, despite that most high-power NSTX discharges were conducted in that configuration. Also, no ohmic H-mode discharges were obtained. As in the START device, H-modes were obtained well above the $60 \mathrm{~kW}$ power threshold predicted for NSTX from a multimachine scaling ${ }^{4}$. Although START's high power threshold was attributed ${ }^{16}$ to high neutral content and edge convective loss, that explanation is questionable for NSTX which has much lower neutral content due to its closer fitting wall and smaller vacuum vessel. Alternately, ST's are predicted to have higher trapped particle fractions owing to the large magnetic field variation ${ }^{2}$ on flux surfaces. This should lead to a higher neoclassical viscosity and poloidal flow damping rate, which could lead to a intrinsically higher power threshold than conventional aspect ratio devices. Detailed calculations are in progress.

Although NSTX wall conditions have been improving ${ }^{10}$ over the long term, they can deteriorate during the course of a single run day, leading to somewhat irreproducible H- 
mode access. This deterioration was manifest in an increasing machine base pressure, from $2 \times 10^{-8}$ torr at the start of the $\mathrm{H}$-mode run day and ending as high as $2 \times 10^{-7}$ torr after eight hours. In the experiment which lead to the longest $\mathrm{H}$-mode discharges, $\mathrm{H}$ modes were produced during five of the first six attempts with NBI, the only failure being due to an NBI fault. However H-mode discharges were not obtained again until late in the day, despite precisely reproducing external conditions of the first five H-modes. The Hmodes later in the day lasted only $10 \mathrm{~ms}$ and could be obtained only at lower $\mathrm{I}_{\mathrm{p}} \sim 700 \mathrm{kA}$. While it is probable that wall conditions affect H-mode access in NSTX, the precise role is unclear at present.

\section{$\underline{\text { H-mode evolution and termination }}$}

H-mode duration in NSTX has ranged from $500 \mu$ s to $65 \mathrm{~ms}$, all shorter than the estimated $\tau_{\mathrm{E}}$ which are of order $100 \mathrm{~ms}$. The first H-modes on NSTX lasted about $8 \mathrm{~ms}$ and were terminated by a localized magnetic reconnection at the periphery, as determined by the USXR data. This MHD event looked very similar to $\mathrm{ELM}^{17}$. There were no low or medium-m precursors in the USXR emission, and the MHD activity (other than H-mode termination) was generally reduced in the H-mode phase compared with the L-mode phases. ELMs in tokamaks and also in the START device ${ }^{3}$ are usually transient outfluxes of particles and energy. Thus, it is unclear why NSTX did not recover an H-mode phase after the ELM-like event.

ELM-like termination in the short $\mathrm{H}$-modes is contrasted with MHD termination in the longer H-modes, which showed a magnetic precursor. For example, the Mirnov activity is observed to increase at $\mathrm{t}=245 \mathrm{~ms}$ during the $\mathrm{H}$-mode in fig. 1(e). The USXR raw data showed a cold, radiative island with poloidal mode number $\mathrm{m}=2$ which began to grow at that time [fig. 4]. This mode had toroidal mode number $n=1$, determined by a toroidal Mirnov array. The growth of this cold island, coupled with the rapid increase of 
the edge carbon emission in the USXR band, suggests that impurities accumulated due to the improvement in particle confinement during the $\mathrm{H}$-mode, and induced a tearing mode due to enhanced radiation near rational mode surfaces, as also observed ${ }^{18}$ in ASDEXUpgrade. In future experiments, impurity accumulation could possibly be eliminated by inducement of regular ELMs, which typically purge the edge plasma of impurities. The fact that these discharges were ELM-free suggests (from tokamak experience) that NSTX was operated close to the L-H power threshold, and that further increase of heating power should induce regular ELMs. The operational challenge to extend the H-modes, then, is to understand and prevent the ELMs from returning the discharge to L-mode, as well as avoiding any $\beta$-related instabilities which may be destabilized due to the increase in heating power used to trigger the H-modes.

\section{Summary}

In summary, we have induced H-mode discharges in NSTX, in which the energy confinement time increased transiently by between 100-300\%. These H-modes had energy confinement well above ELM-free H-mode scaling laws, and had a significantly greater threshold power than predicted. Thus H-modes in NSTX will eventually help extend the confinement and threshold power scalings to low aspect ratio. Finally, $\mathrm{H}-$ modes have broader pressure profiles than L-modes (e.g. the pressure peaking factor was reduced by $\sim 15 \%$ in NSTX), and broad profiles generally have higher $\beta$ limits in tokamaks due to improved low-n kink stability, e.g. TFTR ${ }^{19}$ and DIII-D ${ }^{20}$. Thus achievement of H-modes is a potential path for achieving higher $\beta$ in NSTX.

\section{Acknowledgements}

This research was supported by the U. S. Dept. of Energy under contracts DE-AC0500OR22725, DE-AC02-76-CH0-3073, W-7405-ENG-36, and grant DE-FG02- 
99ER54524. We gratefully acknowledge the contribution of the NSTX technical staff and neutral beam operations staff. 


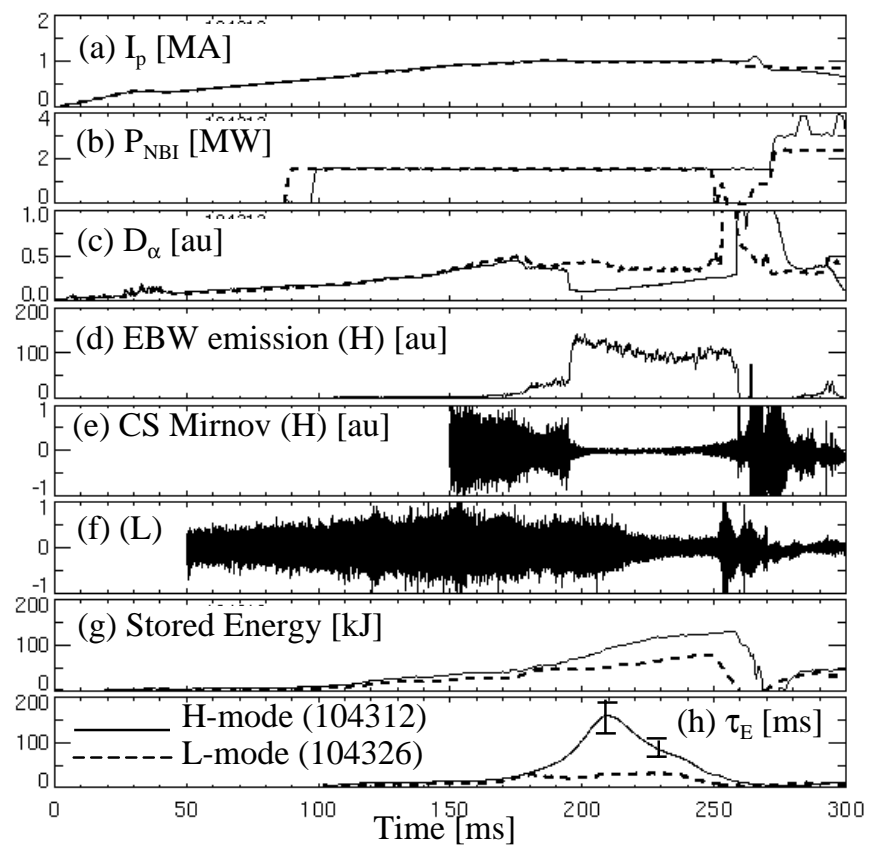

Fig. 1 - Comparison of L-mode (dashed lines in panels) and H-mode (solid lines) discharges in (a) $I_{p}$, (b) NBI power, (c) divertor $D_{\alpha}$ emission, (d) Electron Bernstein Wave (EBW) emission at R=0.85m, (e) Center stack Mirnov signal (H-mode), (f) Center stack Mirnov signal (L-mode), (g) stored energy, and (h) $\tau_{\mathrm{E}}$. Panels (g) and (h) are obtained from EFIT reconstruction. 

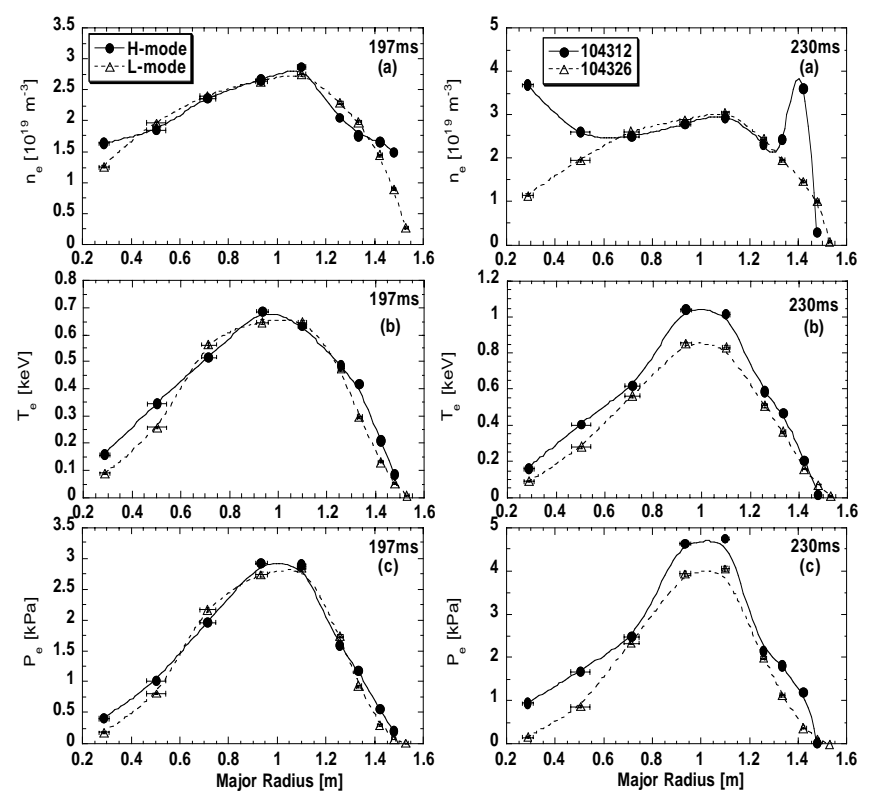

Fig. 2 - Comparison of $n_{e}, T_{e}$, and $P_{e}$ profiles for L-mode and H-mode (a) 5ms after time of the H-mode transition, and (b) 33ms later, during the ELM-free phase. The outer midplane separatrix lies between 1.45 and $1.50 \mathrm{~m}$, and the inner midplane separatrix between 0.19 and $0.22 \mathrm{~m}$. 

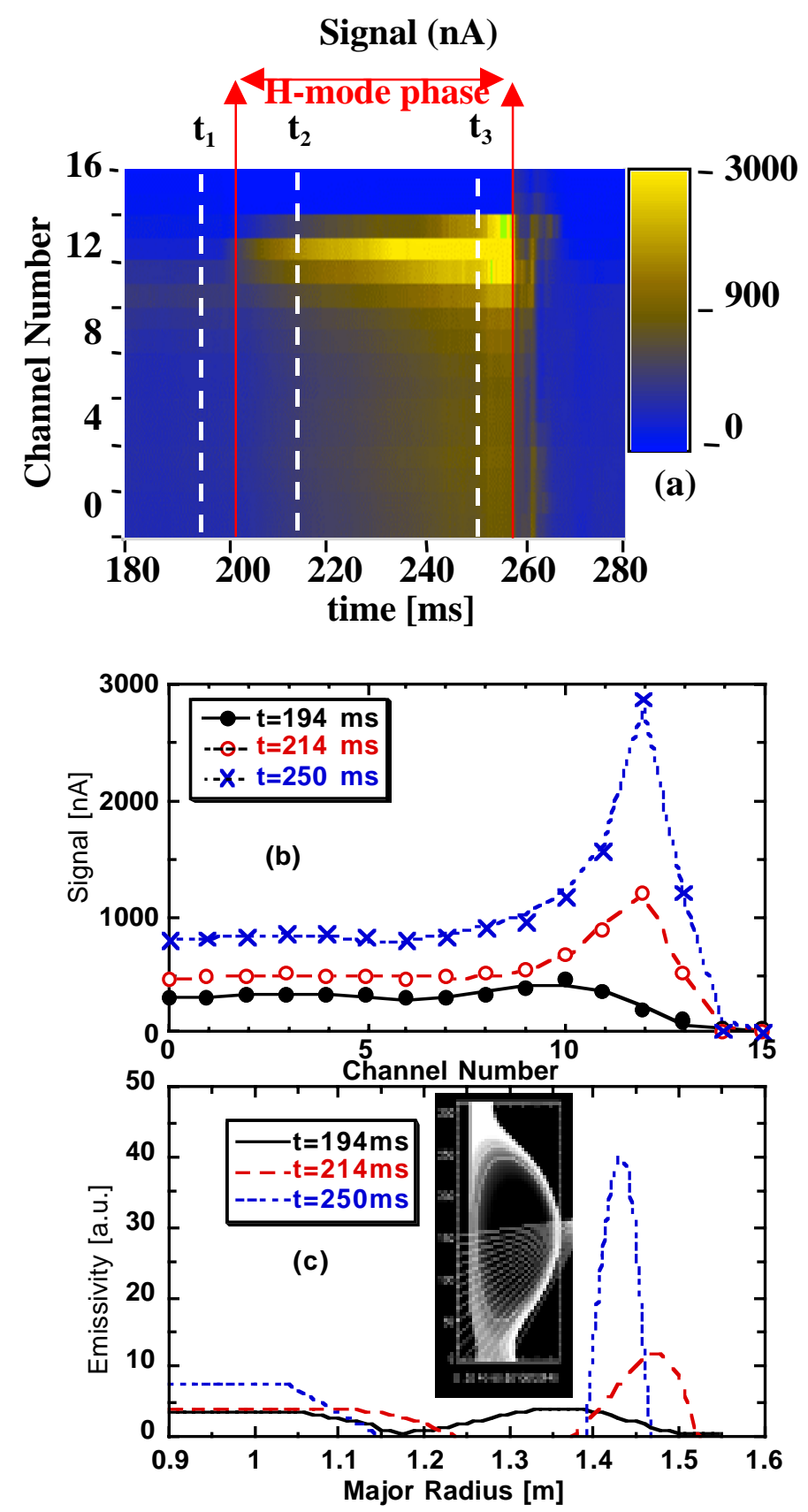

Fig. 3 - USXR profiles showing peaking of the emission at the edge during the H-mode phase: (a) signal vs time and channel, (b) signal vs. channel number, and (c) Abelinverted emissivity for \#104316, a single source H-mode discharge. The three time slices are: $\mathrm{t}_{1}=194 \mathrm{~ms}-\mathrm{L}-\mathrm{mode}$ phase, $\mathrm{t}_{2}=214 \mathrm{~ms}-$ just after $\mathrm{L}-\mathrm{H}$ transition, and $\mathrm{t}_{3}=250 \mathrm{~ms}-$ just before H-mode termination. The geometry of the USXR is an inset in panel (c), with the chord zero nearest the midplane and chord 15 through the divertor. 


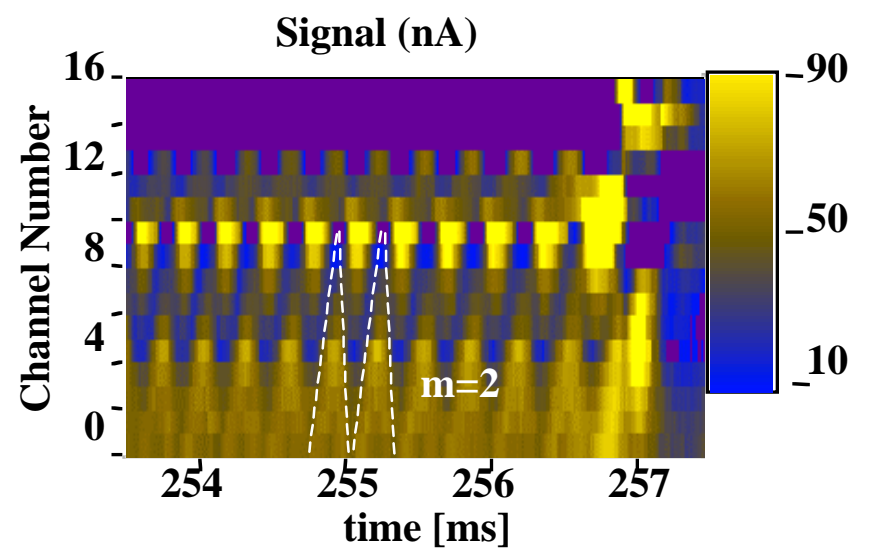

Fig. 4 - USXR spatial and time emission pattern, showing MHD activity onset during ELM-free phase in H-mode and cold-island pre-cursor before termination in \#104316. The mode has $\mathrm{m}=2$ and is an emission 'hole', i.e. a cold island. 


\section{$\underline{\text { References }}$}

${ }^{1}$ F. Wagner et.al., Phys. Rev. Lett. 49, 1408 (1982).

${ }^{2}$ Y-K M. Peng and D.J. Strickler, Nucl. Fusion 26, 769 (1986).

${ }^{3}$ A. Sykes et. al., Phys. Rev. Lett. 84, 495 (2000).

${ }^{4}$ J.A. Snipes, in Proc. of the $24^{\text {th }}$ EPS Conference, Berchtesgaden, Germany (European Physical Society, Geneva, 1997), Pt. III, p. 961.

${ }^{5}$ A. Sykes et. al., Phys. Plasmas 5, 2101 (2001).

${ }^{6}$ ITER physics basis authors, Nucl. Fusion 39, 2137 (1999).

${ }^{7}$ M. Ono et. al., Phys. Plasmas 4, 799 (1997).

${ }^{8}$ C. Neumeyer et. al., Fusion Eng. and Design 54, 275 (2001).

${ }^{9}$ S.M. Kaye et. al., Phys. Plasmas 5, 1977 (2001).

${ }^{10}$ H.W. Kugel et. al., Proc. of $14^{\text {th }}$ Conference on Plasma Surface Interactions in Controlled Fusion Devices, Rosenheim, Germany, May 22-26, 2000, to appear in J. Nucl. Mater.

${ }^{11}$ J. Winter, Plasma Phys. Contr. Fusion Fusion 36, B263 (1994).

${ }^{12}$ C.H. Skinner et. al.,"Effect of Boronization on Ohmic Plasmas in NSTX", submitted to Nucl. Fusion, 4/2001.

${ }^{13}$ G.Taylor, et. al., Rev. Sci. Instrum. 72, 285 (2001)

${ }^{14}$ L.L. Lao et. al., Nucl. Fusion 25, 1611 (1985).

${ }^{15}$ R.A. Hulse, Nucl. Technol./Fusion 3, 259 (1983).

${ }^{16} \mathrm{Yu}$. N. Dnestrovskij et. al., Proc. 26 ${ }^{\text {th }}$ EPS Conf., Maastricht, the Netherlands, p. 178.

${ }^{17}$ ASDEX team, Nucl. Fusion 29, 1959 (1989).

${ }^{18}$ W. Suttrop et. al., Nucl. Fusion 37, 119 (1997).

${ }^{19}$ S.A. Sabbagh et. al., Fusion Energy 1996, 921 (International Atomic Energy Agency, Vienna 1997).

${ }^{20}$ E. A. Lazarus et. al., Fusion Energy 1996, 199 (International Atomic Energy Agency, Vienna 1997). 


\section{External Distribution}

Plasma Research Laboratory, Australian National University, Australia

Professor I.R. J ones, Flinders University, Australia

Professor J oão Canalle, Instituto de Fisica DEQ/IF - UERJ , Brazil

Mr. Gerson O. Ludwig, Instituto Nacional de Pesquisas, Brazil

Dr. P.H. Sakanaka, Instituto Fisica, Brazil

The Librarian, Culham Laboratory, England

Library, R61, Rutherford Appleton Laboratory, England

Mrs. S.A. Hutchinson, JET Library, England

Professor M.N. Bussac, Ecole Polytechnique, France

Librarian, Max-Planck-Institut für Plasmaphysik, Germany

J olan Moldvai, Reports Library, MTA KFKI-ATKI, Hungary

Dr. P. Kaw, Institute for Plasma Research, India

Ms. P.J . Pathak, Librarian, Insitute for Plasma Research, India

Ms. Clelia De Palo, Associazione EURATOM-ENEA, I taly

Dr. G. Grosso, Instituto di Fisica del Plasma, Italy

Librarian, Naka Fusion Research Establishment, J AERI, J apan

Library, Plasma Physics Laboratory, Kyoto University, J apan

Research Information Center, National Institute for Fusion Science, J apan

Dr. O. Mitarai, Kyushu Tokai University, J apan

Library, Academia Sinica, Institute of Plasma Physics, People's Republic of China

Shih-Tung Tsai, Institute of Physics, Chinese Academy of Sciences, People's Republic of China

Dr. S. Mirnov, TRINITI, Troitsk, Russian Federation, Russia

Dr. V.S. Strelkov, Kurchatov Institute, Russian Federation, Russia

Professor Peter Lukac, Katedra Fyziky Plazmy MFF UK, Mlynska dolina F-2, Komenskeho Univerzita, SK-842 15 Bratislava, Slovakia

Dr. G.S. Lee, Korea Basic Science Institute, South Korea

Mr. Dennis Bruggink, Fusion Library, University of Wisconsin, USA

Institute for Plasma Research, University of Maryland, USA

Librarian, Fusion Energy Division, Oak Ridge National Laboratory, USA

Librarian, Institute of Fusion Studies, University of Texas, USA

Librarian, Magnetic Fusion Program, Lawrence Livermore National Laboratory, USA

Library, General Atomics, USA

Plasma Physics Group, Fusion Energy Research Program, University of California at San Diego, USA

Plasma Physics Library, Columbia University, USA

Alkesh Punjabi, Center for Fusion Research and Training, Hampton University, USA

Dr. W.M. Stacey, Fusion Research Center, Georgia Institute of Technology, USA

Dr. J ohn Willis, U.S. Department of Energy, Office of Fusion Energy Sciences, USA

Mr. Paul H. Wright, Indianapolis, Indiana, USA 
The Princeton Plasma Physics Laboratory is operated by Princeton University under contract with the U.S. Department of Energy.

\author{
Information Services \\ Princeton Plasma Physics Laboratory \\ P.O. Box 451 \\ Princeton, NJ 08543
}

Phone: 609-243-2750

Fax: 609-243-2751

e-mail: pppl_info@pppl.gov

Internet Address: http://www.pppl.gov 